\title{
MATIZES DA LINGUAGEM E RESSONÂNCIAS DA EDUCAÇÃO FÍSICA NO ENSINO MÉDIO
}

\author{
LANGUAGE NUANCES AND RESONANCES OF PHYSICAL EDUCATION IN \\ SECONDARY EDUCATION
}

MATICES DEL LENGUAJE Y RESONANCIAS DE LA EDUCACIÓN FÍSICA EN LA EDUCACIÓN SECUNDARIA

\author{
Denise Grosso da Fonseca*, Roseli Belmonte Machado**, \\ Natacha da Silva Tavares*, Sandro Machado*, Luan Abel Pereira Pujol*, \\ Viviane Dulius de Lima*
}

Palavras chave: Educação Física. Linguagem. Ensino Médio.

Resumo: A inserção da Educação Física na Área das Linguagens tem gerado diversos debates. A partir disto, este estudo se propõe a compreender como os professores de Educação Física e os supervisores escolares do Ensino Médio percebem tal inserção. Para tanto, foi feita uma pesquisa situada numa perspectiva pós-estruturalista, desenvolvida em escolas públicas estaduais de Porto Alegre. Este artigo está organizado em cinco seções que apresentam os rumos investigativos, os documentos legais que balizam a discussão, uma reflexão sobre a linguagem, uma análise da posição dos professores e supervisores e as considerações finais sobre 0 estudo. As interpretações indicam que os docentes entrevistados parecem evidenciar diferentes percepções sobre o lugar da Educação Física nesse novo desenho curricular. Prevalece a ideia de linguagem como comunicação e expressão, desafiando-nos a refletir sobre as possibilidades de ampliar a discussão no âmbito da formação inicial e continuada de professores.

Keywords: Physical education. Language. Education, primary and secondary.

Palabras clave: Educación Física. Lenguaje. Educación secundaria.
Abstract: The inclusion of Physical Education in the Languages Area has generated several debates. From that perspective, this study aims to understand how high school Physical Education teachers and school supervisors carry out such integration. A study from a post-structuralist perspective was developed in public schools in Porto Alegre. This paper is organized in five sections, as follows: investigative direction; legal documents guiding the debate; reflection on language; analysis of teachers' and supervisors' positions; and final considerations. Interpretations indicate that teachers interviewed seem to have different perceptions on Physical Education's role in the new curriculum. The idea of language as communication and expression prevails, challenging us to reflect on the possibilities of expanding the discussion in initial and continuing teacher training.

Resumen: La inclusión de la Educación Física en el Área de Lenguajes ha generado diversos debates. En esta perspectiva, este estudio tiene como objetivo comprender cómo los profesores de Educación Física y los supervisores escolares de la enseñanza secundaria ven dicha integración. Para ello, fue realizado un estudio desde una perspectiva posestructuralista, desarrollado en las escuelas públicas de Porto Alegre. Este artículo está organizado en cinco secciones que presentan: las líneas de investigación, los documentos legales que guían la discusión, un debate sobre el lenguaje, un análisis de la postura de maestros y supervisores y las consideraciones finales sobre el estudio. Las interpretaciones indican que los profesores entrevistados parecen mostrar diferentes percepciones sobre el papel de la Educación Física en el nuevo diseño curricular. Prevalece la idea del lenguaje como comunicación y expresión, desafiando a reflexionar sobre las posibilidades de ampliar la discusión en el ámbito de la educación inicial y continua de los maestros.
* Universidade Federal do Rio Grande do Sul. Escola de Educação Física. Porto Alegre, RS, Brasil. E-mail: dgf.ez@terra.com.br; natacha 760@ hotmail.com natacha_760@hotmail.com; luan.pujol@gmail.com; vdulius@yahoo.com.br

** Fundação Universidade de Rio Grande. Rio Grande, RS, Brasil. E-mail: robelmont@yahoo.com.br

Recebido em: 21-10-2016 Aprovado em: 12-04-2017

(c) (i) () Licence 


\section{PALAVRAS INICIAIS}

A Educação Física Escolar brasileira atravessa um momento de ressignificação de valores entendidos até hoje como centrais na constituição de uma ou mais concepções que, historicamente, Ihe foram atribuídas como próprias. Ao longo do século $\mathrm{XX}$, chegando à contemporaneidade, a especificidade da Educação Física, enquanto componente curricular, esteve ligada a discursos oriundos, sobretudo, da Biologia e da Psicologia (BETTI, 2005). A inserção da Educação Física na Área das Linguagens - a partir de decisões legislativas e propostas curriculares para a Educação Básica - tem gerado diversos debates sobre esse novo "lugar" para o qual a Educação Física foi deslocada. Trata-se de uma reconfiguração curricular que tem permitido novas análises sobre seus desdobramentos nas trilhas escolares. A concepção de linguagem dos Parâmetros Curriculares Nacionais para o Ensino Médio (PCNEM) apontava a seguinte direção:

\footnotetext{
A linguagem é considerada como capacidade humana de articular significados coletivos em sistemas arbitrários de representação, que são compartilhados e que variam de acordo com as necessidades e experiências da vida em sociedade. A principal razão de qualquer ato de linguagem é a produção de sentido (BRASIL, 2000, p. 125).
}

Cabe destacar que o documento supracitado apresenta uma concepção de linguagem que perpassa as concepções específicas contempladas em cada componente, possuindo, ela mesma, uma natureza transdisciplinar. Nesse sentido, uma das novas tarefas do professor de Educação Física é a de pensar experiências para a sua prática pedagógica a partir dessa nova matriz na qual está inserida, levando em conta a perda das antigas referências, ao menos no que se refere aos documentos legais.

Para dar conta de tal temática, foi desenvolvido um projeto de pesquisa intitulado " $\mathrm{A}$ Educação Física na Área das Linguagens: Propostas Curriculares e Prática Pedagógica", que tem por objetivo analisar as transformações/deslocamentos da Educação Física na Educação Básica a partir de sua inserção na referida área. Uma das frentes do projeto, que será apresentada neste artigo, propõe-se a compreender como os professores e os supervisores escolares do Ensino Médio percebem a inserção da Educação Física na Área das Linguagens. Este artigo está organizado em cinco seções, que apresentam os rumos investigativos, uma discussão sobre os documentos legais que balizam a inserção da Educação Física na área das Linguagens, um aprofundamento sobre o tema linguagem, a análise da posição dos professores e supervisores sobre o tema destacado e as considerações finais sobre o estudo.

Importante destacar que esta pesquisa foi desenvolvida nos anos 2015 e 2016 sob orientações legislativas e pedagógicas, legitimadas por amplas e profundas discussões entre os pares. Nesse sentido, não estamos considerando a recente Medida Provisória 746/2016 (BRASIL, 2016b), a qual rompe com importantes discussões e construções pedagógicas que vinham se desenvolvendo em nosso país.

\section{OS RUMOS INVESTIGATIVOS}

Esta pesquisa situa-se numa perspectiva pós-estruturalista, de pensar e de debater as questões relativas à educação, que: 
[...] reconhece o descentramento da consciência e do sujeito, a instabilidade e provisoriedade das múltiplas posições em que são colocados pelos múltiplos e cambiantes discursos em que são constituídos, começa por questionar e interrogar esses discursos, desestabilizando-os em sua inclinação a fixá-los numa posição única que, afinal, se mostrará ilusória (SILVA, 1994, p. 251).

Entendendo-se que não temos um sujeito fixo, estático, mas um indivíduo que é constantemente construído e transformado em sujeito pelas múltiplas relações e pelos discursos em que está imerso, propõe-se a realização desta pesquisa analisando os discursos presentes nos documentos oficiais que regulam a inserção da Educação Física na Área das Linguagens, além da análise de entrevistas semiestruturadas. Para este recorte contamos com as informações advindas de entrevistas realizadas com cinco professores de Educação Física e dois supervisores pedagógicos de duas escolas da rede estadual no município de Porto Alegre.

Entrevistas semiestruturadas possibilitam obter informações por meio de questões concretas que são definidas anteriormente e, ao mesmo tempo, permitem ao pesquisador explorar informações não previstas (NEGRINE, 2010). As entrevistas foram realizadas considerando os seguintes aspectos na organização das perguntas: a) mobilização da escola para estudos, reflexões e debates sobre as novas DCNs e Proposta Pedagógica do Estado para o Ensino Médio; b) inserção da Educação Física nas discussões; c) organização curricular; d) organização do trabalho por áreas de conhecimento; e) prática pedagógica interdisciplinar; f) inclusão da Educação Física na área das linguagens e g) dificuldades encontradas e formas de enfrentamento.

Os discursos presentes nos documentos oficiais e nas entrevistas realizadas com os sujeitos da pesquisa tomam por base o refinamento que Foucault (2008) atribui ao termo discurso no desenrolar de sua obra. Foucault assume a linguagem como constitutiva de nosso pensamento (VEIGA-NETO, 2007). Nesse sentido, destacamos que todos nós nascemos dentro de um mundo que já é de linguagem, em que os discursos já estão circulando há muito tempo. "O discurso não é simplesmente aquilo que traduz as lutas ou os sistemas de dominação, mas aquilo por que, pelo que se luta, o poder do qual nos queremos apoderar" (FOUCAULT, 2008, p. 10).

Nessa perspectiva, consideramos que o discurso não possui apenas um sentido, uma verdade, mas está intrinsecamente conectado a uma história, ou seja, não é uma mera referência a algo. 0 discurso faz parte de uma rede maior que o precede e o engloba; ele é parte de uma formação discursiva, sendo do mesmo modo constituído por um conjunto de enunciados. Como afirma Veiga-Neto, "[...] os discursos não estão ancorados ultimamente em nenhum lugar, mas se distribuem difusamente pelo tecido social, de modo a marcar o pensamento de cada época, em cada lugar, e, a partir daí, construir subjetividades" (VEIGANETO, 2007, p. 100).

Apoiados nessas considerações, entendemos que os sujeitos entrevistados em nossas pesquisas estão intrinsecamente conectados a toda a formação discursiva que os sujeitou a argumentarem de uma ou de outra maneira, reforçando certo regime de verdade, e submetidos inegavelmente a relações de poder. Seus discursos, materializados nas falas, são parte de verdades que há muito tempo circulam e os constituem de um ou de outro modo. Ao mesmo tempo, ao analisarmos os documentos que regulam a Educação Física como parte da Área 
das Linguagens, percebemos que essa posição não é neutra, mas responde a um regime de verdade que a posiciona nesse lugar. Desse modo, afirmamos que a escolha por operar com esse conceito é um modo de entender os efeitos de determinados discursos, que são parte de uma verdade que está constituída nos diferentes sujeitos.

\section{A BASE LEGAL DA ÁREA DA LINGUAGEM E A EDUCAÇÃO FÍSICA NO ENSINO MÉDIO}

A Lei de Diretrizes e Bases da Educação Nacional/LDBEN, 9394/96 (BRASIL, 1996) estabelece no artigo 26, no §3- que a Educação Física é componente curricular da Educação Básica, tendo sua redação alterada na Lei no 12.796 de 2013, que inclui a sua obrigatoriedade, respaldando legalmente a Educação Física nos currículos escolares do Brasil. Aprovado em 1ำ de junho de 1998, o Parecer da Câmara de Educação Básica/CEB do Conselho Nacional de Educação/CNE traz propostas de regulamentação da base curricular nacional e de organização do Ensino Médio (BRASIL, 1998), apresentando a Educação Física inserida na Área das Linguagens. Em 26 de junho do mesmo ano, a Resolução CEB № 2 institui as DCNEM (BRASIL, 2012), que prevê para a Área das Linguagens - dentre outras atribuições - possibilitar que os educandos compreendam e usem "[...] os sistemas simbólicos das diferentes linguagens como meios de organização cognitiva da realidade pela constituição de significados, expressão, comunicação e informação [...]" confrontem "[...] opiniões e pontos de vista sobre as diferentes linguagens e suas manifestações específicas" (BRASIL, 2012, p.4).

Esses documentos enunciam a concepção de desenvolver as disciplinas e seus conteúdos através de áreas de conhecimento, discutindo a ideia de um currículo mais interdisciplinar, visando o desenvolvimento de habilidades e competências. 0 parecer de 1998 também expressa que um dos desafios dessa organização curricular é "[...] trabalhar as linguagens não apenas como formas de expressão e de comunicação, mas como constituidoras de significados, conhecimentos e valores" (BRASIL, 1998, p. 37). O documento também afirma que as disciplinas identificadas nesta área, além da Língua Portuguesa, são aquelas que correspondem a outras formas de comunicação, como as Artes, as Atividades Físicas ${ }^{1}$ e a Informática, evidenciando a importância de todas as linguagens como parte de conhecimentos e identidades (BRASIL, 1998, p. 59).

A linguagem, nos referidos documentos, é entendida como uma herança social, uma "realidade primeira" (BRASIL, 2000, p. 5). A linguagem permeia o conhecimento e as formas de conhecer, tendo como grande objetivo, nesse sentido, a interação e a comunicação com o outro dentro de um espaço social. Conforme apontam os documentos citados, toda linguagem carrega dentro de si uma visão de mundo.

Dentro desse entendimento, a Educação Física, enquanto produtora de experiências corporais, precisa "[...] buscar sua identidade como área de estudo fundamental para a compreensão e entendimento do ser humano" (BRASIL, 2000, p. 34). Sua inserção na Área das Linguagens se dá na medida em que o corpo é visto, ao mesmo tempo, como modo e meio de integração do indivíduo na realidade do mundo, em que cada movimento corporal possui

1 Em um estudo realizado em 2010 e publicado na revista Movimento, Lazzarotti Filho et al. (2010), com o objetivo de identificar os significados com os quais o termo "práticas corporais" vem sendo utilizado na literatura acadêmica brasileira, argumentam que o termo aparece pela primeira vez em 1995, em artigo publicado pelo professor Alex Branco Fraga. O termo anteriormente usado era atividade física. Para os autores "no campo da Educação Física, o termo 'práticas corporais' vem sendo valorizado pelos pesquisadores que estabelecem relação com as ciências humanas e sociais, pois aqueles que dialogam com as ciências biológicas e exatas operam com o conceito de atividade física" (LAZZAROTTI FILHO et al., 2010, p. 25). 
um significado que the é atribuído (BRASIL, 2000, p. 38). A organização do conhecimento em áreas pretende criar condições para que a prática escolar ocorra numa perspectiva de interdisciplinaridade.

Em 2009 o Referencial Curricular do Rio Grande do Sul também apresenta a organização das disciplinas em áreas, sendo a Área das Linguagens, Códigos e suas Tecnologias composta pelas disciplinas de Língua Portuguesa e Literatura, Língua Estrangeira Moderna, Arte e Educação Física. Neste documento apresenta-se o entendimento de linguagem como "a capacidade humana de articular significados coletivos em códigos, ou seja, em sistemas arbitrários de representação, compartilhados e variáveis, e de lançar mão desses códigos como recursos para produzir e compartilhar sentidos" (RIO GRANDE DO SUL, 2009, p. 37). 0 Referencial propõe entender as linguagens como formas dos sujeitos estarem e se comunicar no mundo, como modo de construir e reconstruir significados e culturas "historicamente construídas e dinâmicas" (RIO GRANDE DO SUL, 2009, p. 37).

As DCNs de 2013 mantêm a organização das disciplinas por áreas de conhecimento. Além disso, enfatizam a busca por interdisciplinaridade e integração entre componentes e áreas nas escolas. A Proposta Pedagógica para o Ensino Médio Politécnico e Educação Profissional Integrada ao Ensino Médio, da Secretaria de Educação do Rio Grande do Sul, também prevê o trabalho através das áreas de conhecimento, buscando garantir a interdisciplinaridade (RIO GRANDE DO SUL, 2011).

Os documentos preliminares da Base Nacional Comum Curricular/BNCC (BRASIL, 2015) apoiados nas DCNs reafirmam a proposta de organização dos componentes curriculares por áreas de conhecimento, mantendo a Educação Física na Área das Linguagens. A linguagem é entendida, na versão preliminar da BNCC, como meio para a comunicação. As práticas de linguagem são entendidas como formas de construção de significados coletivos. "As práticas de linguagem permitem a construção de referências e entendimentos comuns para a vida em sociedade e abrem possibilidades de expandir o mundo em que se vive, ampliando os modos de atuação e de relacionar-se" (BRASIL, 2015, p, 86). No documento da BNCC se expressa que existe uma multiplicidade de linguagens a serem aprendidas

[...] verbal, musical, visual e corporal, e para a integração desses recursos expressivos na participação na vida social. 0 termo abrange também diferentes formas de experiências: estéticas, sensoriais, sensíveis, corporais, sonoras, cinestésicas, imagéticas, performativas (BRASIL, 2015, p.86).

O documento aponta para as diversas possibilidades e funções da linguagem, sinalizando que esta, ao mesmo tempo em que possui a tarefa de comunicação, também produz e reproduz desigualdades. A prática da linguagem pode gerar conflitos em função de "representações sobre a realidade" (BRASIL, 2015, p.86), mas também possui papel na construção de identidades. A partir disso, o documento propõe que a Área das Linguagens trabalhe no sentido de possibilitar a ampliação das capacidades de expressão dos estudantes e a compreensão de como as diferentes manifestações de linguagem se constroem e se produzem.

$\mathrm{Na}$ Educação Física, as práticas corporais são apresentadas como objeto de conhecimento com a finalidade de codificação e significação social. $O$ documento propõe que as práticas corporais sejam trabalhadas não apenas no sentido de reprodução, mas de produção de sentidos e significados. São estipulados para a Educação Física objetivos orientados pelas 
seguintes competências: fruir, experimentar, usar, apropriar, refletir sobre a ação, construir valores, analisar, compreender e protagonizar. A Educação Física é sustentada na Área das Linguagens, neste documento, pelos seguintes elementos:

a) ampliar as possibilidades de uso das práticas de linguagens; b) conhecer a organização interna dessas manifestações; c) compreender 0 enraizamento sociocultural das práticas de linguagens e o modo como elas estruturam as relações humanas (BRASIL, 2015, p. 101).

A partir desta breve retomada nas bases legais acerca da construção e da composição da Área das Linguagens, é possível perceber que não se configura um consenso acerca do conceito de linguagem nos diferentes documentos. Primeiramente podemos identificar que alguns dos documentos empreendem um esforço em conceituar ou apresentar um entendimento de linguagem, enquanto outros parecem tomar tal questão como resolvida, sem necessidade de aprofundamento. Ao mesmo tempo, o fato de alguns documentos não se deterem a explicar o que define cada área de conhecimento pode significar que tal distribuição de componentes por área seja mais organizacional do que epistemológica.

Os documentos que se dedicam a conceituar ou explicitar os entendimentos de linguagem, que sustentam suas propostas, parecem indicar uma compreensão não consensuada ou homogênea de linguagem. Alguns trechos ou expressões utilizadas parecem se sustentar em uma perspectiva mais estruturalista de entender a linguagem - como a relação com a aquisição de códigos e signos -, enquanto outras colocações indicam um movimento interpretativo mais identificado com perspectivas pós-estruturalistas de compreender as linguagens - como a produção de sentidos e significados, a construção de discursos a partir do uso da linguagem e as relações de poder envoltas na construção das linguagens.

\section{REFLEXÕES SOBRE A LINGUAGEM}

O termo linguagem, dependendo da perspectiva do nosso olhar, pode ter vários sentidos. Podemos considerar seus usos desde o significado atribuído no dicionário, para 0 qual a linguagem significa

[...] 1 o conjunto das palavras e dos métodos de combiná-las usado e compreendido por uma comunidade, 2 capacidade de expressão, esp. Verbal, 3 meio sistemático de expressão de ideias ou sentimentos com o uso de marcas, sinais, ou gestos convencionados 4 qualquer sistema de signos ou sinais 5 linguajar" (HOUAISS, 20102, p. 480).

$\mathrm{Na}$ legislação educacional que regula o componente curricular Educação Física, por exemplo, encontramos diferentes definições de linguagem, conforme já descrito em seção anterior. A principal delas, ou a mais usada, parece ser a definida nos Parâmetros Curriculares Nacionais para o Ensino Médio, que entende o termo como a "capacidade humana de articular significados coletivos em sistemas arbitrários de representação" (BRASIL, 2000, p. 125). De um âmbito geral poderíamos, em nossos estudos, nos filiar tanto aos entendimentos previstos tanto na legislação educacional, quanto à definição padronizada de significados trazida nos dicionários de Língua Portuguesa. Todavia, inscritos numa perspectiva de estudo que compreende que as verdades são invenções deste mundo (FOUCAULT, 1988), resolvemos aprofundar nossa concepção sobre o significado de linguagem, mantendo a vontade de problematizar a recente conexão da Educação Física com esse termo. 
A busca por problematizar os significados do termo linguagem nos conduz a um olhar de inspiração genealógica, o qual abrange uma postura de pesquisa comprometida com uma "metodologia que busca o poder no interior de uma trama histórica, em vez de procurá-lo em um sujeito constituinte" (FOUCAULT, 1988, p. 7). Trata-se de um processo não linear e que não recorre a todos os fatos que possuem ligação com determinado artefato, mas que olha as rupturas, os encontros e desencontros de tramas históricas que constituem sujeitos e verdades. Nessa perspectiva, nos propusemos a olhar os principais entendimentos de uma filosofia da linguagem, recorrendo a autores que entre os séculos XX e XXI tematizaram a linguagem para, a partir dessa compreensão, colocar as lentes pelas quais olharíamos para 0 nosso objeto de estudo.

Dentro de um modo de conceber a linguagem, filósofos hoje chamados de uma vertente estruturalista entendem a linguagem como representacional do mundo. Dentz e Lamar (2008) nos lembram que, desde Platão, a linguagem era vista como possível de dar conta e de descrever, de forma adequada, uma correspondência entre conhecedor e conhecido, um instrumento capaz de designar o que foi percebido pela experiência humana.

Dentre os autores que transitam em uma perspectiva estruturalista, Saussure (2006, p.27) defende que o estudo da linguagem comporta duas partes: "[...] a língua que é social em sua essência e independente do indivíduo; esse estudo é psíquico; outra, secundária, tem por objeto a parte individual da linguagem, a fala, inclusive a fonação, e é psicofísica". Portanto para o autor língua e fala são fenômenos distintos. A língua é um sistema de signos que expressam ideias e sua sede se encontra no cérebro. Os signos são constituídos pelo conceito ou significado e a imagem acústica ou significante. Assim, superando a ideia de que a língua é apenas uma lista de termos que corresponde a outras coisas, "[...] o signo linguístico une não uma coisa e sua palavra, mas um conceito e uma imagem acústica” (SAUSSURE, 2006, p.80).

$\mathrm{Na}$ esteira de pensamento de Saussure, Bakhtin (1992) trabalha com a ideia de linguística da enunciação, apoiado no materialismo histórico-dialético. 0 autor discute a linguagem como uma construção que se dá através das relações sociais; para ele, a linguagem cumpre uma função de comunicação e apropriação da cultura. De acordo com Bakhtin (1992), o que é ideológico possui um significado, é um signo. Daí o conceito de signo linguístico, entendido como um elemento representativo constituído por dois aspectos, o significante (imagem mental) e o significado (imagem sensorial).

Com o advento da chamada virada linguística, essas noções são deslocadas. A linguagem deixa de ser percebida como uma representação da realidade ou como fixa e centrada em um significado e passa a ser considerada como parte que integra, define e constitui a própria realidade (SILVA, 1999). A linguagem não é capaz de encerrar um significado, mas é compreendida dentro de relações que a precedem e a englobam.

\footnotetext{
A chamada "virada linguística" na teorização social e em outros campos começa por desalojar o sujeito do humanismo e sua consciência do centro do mundo social. A filosofia da consciência, firmemente assentada na suposição da existência de uma consciência humana que seria a fonte de todo significado e toda ação, é deslocada em favor de uma visão que coloca em seu lugar o papel das categorizações e divisões estabelecidas pela linguagem e pelo discurso, entendido como o conjunto dos dispositivos linguísticos pelos quais a "realidade" é definida. A autonomia do sujeito e de sua consciência cede lugar a um mundo social constituído em anterioridade e precedentemente àquele sujeito, na linguagem e pela linguagem (SILVA, 1999, p. 248).
} 
Para Veiga-Neto e Lopes (2007) expressões como "a coisa em si" ou "o fato em si" não possuem nenhum sentido no registro da virada linguística. As coisas e os fatos estão relacionados com aqueles que pensam sobre essas coisas ou esses fatos, "trata-se de uma relação (também sempre contingente) que se estabelece entre cada um que pensa, conhece e diz e a coisa que é pensada, conhecida e dita" (VEIGA-NETO E LOPES, 2007, p. 23).

Inspirados por esse entendimento de linguagem, entendemos que a inserção da Educação Física na Área das Linguagens não pode ser vista como um ato simples. Para alguns, esse movimento significa pensar que a Educação Física deve passar a trabalhar dentro de uma chamada linguagem corporal, em que saberes referentes ao corpo ou à expressão corporal seriam mais evidenciados do que outros conhecimentos. Essa é uma visão que restringe 0 termo linguagem à "coisa em si", visão que estamos buscando superar nesta reflexão. 0 termo não é atributivo de alguns poucos significados, não é reducionista.

Todavia, ressaltamos que, por nos filiarmos a um entendimento de que a linguagem não representa a coisa em si, mas a constitui, compreendemos que nosso principal objetivo nesta pesquisa está mais comprometido em debater os efeitos que a presença/integração da Educação Física na Área das Linguagens traz aos diversos sujeitos do que buscar definir como é mesmo, ou "a coisa em si" que a Educação Física, agora inserida nessa área, deva ser. 0 movimento do pensamento está nessa esteira de problematizar as questões para pensar os modos como foram constituídas, postas em circulação e seus efeitos, ao invés de definir a Educação Física em algum lugar numa operação que, talvez, fosse bastante reducionista.

\section{UM OLHAR PARA PROFESSORES E SUPERVISORES}

Para compor essa discussão, trazemos falas dos colaboradores entrevistados, analisando/comparando as compreensões dos professores de Educação Física e dos supervisores pedagógicos sobre a Educação Física e a Área das Linguagens. Os sujeitos pesquisados estão identificados pelas letras do alfabeto para preservar suas identidades. Para melhor ilustrar nossas percepções, trazemos ao longo do texto comparativos entre as respostas dos docentes e dos supervisores.

Iniciamos com as considerações coletadas em uma das escolas. Ao responder sobre como está a inserção da Educação Física na área, a supervisora dessa escola responde:

A Educação Física faz parte da Área de Linguagens e eu tenho tido muitas oportunidades de observar a atuação da Educação Física que deixou um pouco de ser só campo, só jogos. Nós estamos trabalhando sempre com projetos, então um dos projetos foi identidade do aluno. Então eles, Linguagens, se encarregaram de trazer propostas, história de pessoas, biografias de pessoas e a partir dessa biografia a gente começou a inserir o aluno. Então, a partir desse projeto, a Educação Física teve oportunidade de lançar para esse aluno conhecimento da nutrição e do movimento (SUPERVISORA BE).

Já a professora de Educação Física da mesma escola assim se manifesta sobre essa questão:

Eu não concordo em simplesmente incluir na Área das Linguagens. Porque a Educação Física se assemelha muito com a Biologia, com a Física e Química, e até com a Matemática. A gente utiliza muito. Então nós, as Linguagens é a parte mais difícil de trabalhar com interdisciplinaridade. Eu sei que a linguagem corporal, 
a linguagem escrita, estão ligadas, porém pra tu fazer um projeto correto e colocar a Língua Portuguesa ou Inglês e a Educação Física é mais complicado do que tu trabalhar em Matemática com figura, trajetória na Física, Biologia no conhecimento do corpo. É até mais fácil, entendeu? (PROFESSOR AD).

Temos nas falas dos dois sujeitos compreensões distintas, que, de alguma forma, nos levam a refletir sobre esse movimento. A professora da supervisão percebe um avanço a partir da entrada da Educação Física na Área das Linguagens, pois, segundo ela, a Educação Física deixou de "ser só campo, só jogos" e passa a compor os projetos da escola. Já a professora de Educação Física nos relata que fica mais difícil refletir as questões da Educação Física a partir de uma matriz como a das Linguagens. Poder se enxergar enquanto docente da Área das Linguagens é um exercício que demanda um nível de desconstrução de certas identidades há tempos estabelecidas nesse contexto. Inserida numa lógica biologicista, a professora tem dificuldades para ver essa nova relação. Além disso, para a professora, ao entrar na Área das Linguagens, a Educação Física parece ficar resumida a um trabalho relacionado à expressão de uma linguagem. Ou seja, para ela, o termo Área das Linguagens — numa concepção talvez estruturalista da "coisa em si" - encerra o trabalho a ser desenvolvido na Educação Física dentro da linha de uma expressão da linguagem corporal.

Por outro lado, ao perceber um movimento de deslocamento conceitual da Educação Física para a Área das Linguagens, essa professora pode ter condições de compreender o caráter contingente que o termo linguagem pode ter. Isso permite que possamos refletir sobre até que ponto é produtivo dispor a Educação Física a partir de apenas uma matriz, pois, pra muitos docentes, relacionar a Educação Física a uma área significa, igualmente, restringi-la a essa área.

Em outra escola, sobre a inserção da Educação Física na Área das Linguagens, as falas dos professores apontam:

Eu acho que hoje o professor, trabalhando por área, consegue ter uma concepção de educação muito mais ampla. Tu amplias a visão de educação, tu consegues perceber que a dificuldade do aluno não é só contigo. Aí tu consegues enxergar o aluno de uma outra forma. (PROFESSOR RE).

Esse professor destaca a importância do trabalho por área pela possibilidade que oferece de ampliar a visão sobre o aluno bem como sobre a Educação. Nesse sentido somos desafiados a problematizar a lógica curricular que se estabelece num currículo por áreas em relação a um currículo disciplinar. Considerando a visão de Silva (2011) de que o currículo pode ser entendido como uma questão de poder, na fala do professor parece haver um compartilhamento da responsabilidade/poder sobre a aprendizagem dos alunos pela possibilidade de interlocução entre os diferentes componentes curriculares da área. 0 professor, ao considerar o compartilhamento entre as disciplinas como algo benéfico para todos, também, de certo modo, está colocando em operação relações de poder afirmando sua preferência por um trabalho articulado entre as disciplinas.

Outro professor, também da mesma escola, expressa sua visão colocando como uma limitação o pertencimento da Educação Física à área em pauta.

Quando se pensa em Educação Física e a Área de Linguagens, parece que só tem a expressão corporal, a linguagem corporal para oferecer, enquanto que com os outros componentes da área das Ciências da Natureza a contribuição é muito mais ampla, muito maior (PROFESSOR AN). 
Há uma divergência entre posicionamentos dos docentes sobre a inserção da Educação Física na Área das Linguagens. Um professor enxerga potencialidades num currículo por área e destaca a visão do todo sobre 0 aluno; já o outro percebe dificuldades no trabalho a ser desenvolvido, destacando que a Educação Física não deveria estar nessa área. Para 0 professor, tal movimento torna o trabalho da Educação Física bastante restritivo à linguagem $e$ à expressão corporal. Centrado numa visão biologicista da Educação Física, o docente destaca e reivindica sua composição junto à Área das Ciências da Natureza. Vemos, novamente, um professor conexo a um entendimento de linguagem como a "coisa em si" no sentido restrito do que significa linguagem numa visão estruturalista do termo. Para ele, por estar nessa área, outros conteúdos não podem ser desenvolvidos, pois não são "linguagem".

Ao ser questionado sobre o atual projeto do Estado do Rio Grande do Sul e sobre 0 funcionamento desta organização na Educação Física, o professor relata certa intimidade em relação aos conhecimentos em decorrência de sua formação, respondendo que:

Até na época de estudos, pro próprio concurso, a gente tem um contato preliminar, assim, com estes assuntos, mas de fato, é na escola que a gente se inteira mais e começa a trabalhar com estas questões (PROFESSOR AN).

Sobre o trabalho por áreas, a supervisora pedagógica comenta:

Nós tínhamos antigamente as reuniões comuns, não é? A gente reunia todos os professores e falávamos todas as dificuldades, o que nós tínhamos que resolver. A partir do Pacto houve a necessidade de termos então a hora atividade obrigatória do professor. Foi o primeiro incentivo dado para que pudéssemos fazer essa mudança. Então organizamos a escola por áreas e hora atividade (SUPERVISORA SI).

Essa fala da supervisora retrata a tentativa de articulação interdisciplinar entre os componentes da área; porém, ao analisarmos as falas anteriores dos professores da mesma escola dessa supervisora, percebemos que há avanços, mas ainda há dificuldades a serem sanadas no que diz respeito a um trabalho interdisciplinar e na inserção da Educação Física na Área das Linguagens. Para a primeira professora, a "RE", "hoje o professor, trabalhando por área, consegue ter uma concepção de educação muito mais ampla". Já para o segundo professor, o "AN", "quando se pensa em Educação Física e a Área de Linguagens parece que só tem a expressão corporal, a linguagem corporal pra oferecer". Vemos uma diferença na fala dos docentes, pois, enquanto a primeira amplia seu olhar sobre o processo educativo interdisciplinar, o outro professor ainda manifesta uma dificuldade de inserção da Educação Física na área.

Refletimos que fomos forjados numa lógica em que buscamos sempre um suposto fio condutor que permita amarrar todos os elementos de um determinado fato ou ideia num único conjunto (VEIGA NETO; LOPES, 2007). Nesse sentido, a noção de pertencimento a uma classe, no caso a Educação Física na Área das Linguagens, depende do que estipulamos ser a classe, ou com quais regimes de verdade conectamos o conceito de Educação Física. Assim, ao nos depararmos com as dificuldades expostas e evidenciadas na escola, desafiamo-nos a pensar que todo entendimento, ou tipos de pensamento, estão comprometidos ou relacionados a aspectos e valores sociais e culturais.

Além disso, percebemos que a escola continua com dificuldades no diálogo interdisciplinar entre áreas do conhecimento. Os professores de Educação Física parecem 
não compreender seu lugar entre as disciplinas que compõem a Área das Linguagens. Mesmo que as políticas apontem para essa lógica, alguns professores não conseguem fazer esse deslocamento. Nesse sentido, podemos problematizar outro ponto. Talvez muitos dos professores ainda se percebam dentro de outros lugares em que a Educação Física estava, o que provoca, de certo modo, a conexão com uma identidade diferente da que está sendo proposta.

\section{ALGUMAS REFLEXÕES POSSÍVEIS}

A análise das falas de professores de Educação Física e das supervisoras pedagógicas que colaboraram com este estudo nos traz elementos que permitem expressar nossa compreensão de que a inclusão da Educação Física na Área das Linguagens está sendo um processo com múltiplos matizes a partir dos diferentes atores que percorrem as trilhas da docência nas escolas pesquisadas. Para as supervisoras, alguns movimentos evidenciam deslocamentos ao encontro de novas perspectivas para o trabalho docente, tais como 0 trabalho com projetos e novos arranjos na organização de horários para possíveis trocas entre professores por áreas de conhecimento e entre as áreas de conhecimento.

Entretanto, as respostas dos professores entrevistados parecem evidenciar diferentes percepções sobre o lugar da Educação Física nesse novo desenho curricular. Enquanto para uns a visão de educação se ampliou e a escola se apresenta como um lugar de formação continuada, para outros a visão parece ter se restringido, ficando limitada a concepções historicamente legitimadas. Neste cenário, é importante o esforço em não dicotomizar as diferentes percepções enunciadas, mas buscar interpretá-las a partir da ideia de que:

\section{[...] mudanças ainda que se refiram especialmente à reorganização que afetou 0 campo dos saberes, tem também a ver com as relações que se estabeleceram entre saberes e poderes específicos, assim como entre esses e os modos de subjetivação ou, os diferentes tipos de identidades sociais, que se instituíram (VARELA, 1994, p. 87).}

Além disso, trazemos para a discussão o entendimento que os professores e supervisores têm sobre a Área das Linguagens ou, mais especificamente, sobre Linguagem. Nas considerações dos sujeitos da pesquisa, percebemos uma preocupação com o fato de, por estar inserida na Área das Linguagens, a Educação Física se localizar em um trabalho no campo da expressão corporal ou da comunicação, desconsiderando outros aspectos. Nesse sentido, levantamos a discussão refletindo que esta é uma posição que reduz a linguagem a uma ideia de comunicação e de expressão e a Educação Física, pela sua especificidade, pode ser entendida como comunicação e expressão corporal. Isso se relaciona a uma matriz de pensamento que considera a linguagem "como a coisa em si", sem abrir outras reflexões.

Colocando-nos na contramão dessas considerações, tentamos, a partir de outro entendimento que se afina com uma perspectiva que entende a linguagem numa relação entre aquele que pensa e diz a coisa e a coisa que é pensada e dita (VEIGA-NETO; LOPES, 2007), compreender que, mais interessante do que definir como a Educação Física na Área das Linguagens deveria ser, nos preocupamos com os efeitos desses arranjos. Assim, ao analisarmos as respostas dos professores e supervisores, que percebem a Educação Física numa ideia de linguagem como comunicação e expressão, nos preocupamos com outros saberes que estão sendo deixados de lado. Outras possibilidades que a Educação Física no Ensino Médio 
poderia ter, mas, por uma questão de entendimento, estão, por vezes, sendo invisibilizadas ou negligenciadas. Outros saberes, outros objetivos, outros aspectos importantes da Educação Física desconsiderados durante as aulas. Nessa perspectiva, as questões aqui discutidas nos ajudam a olhar para o processo de inserção da Educação Física na Área das Linguagens como mais um desafio a problematizar nossas reflexões, bem como as possibilidades de ampliar a discussão no âmbito da formação inicial e continuada de professores.

\section{REFERÊNCIAS}

BAKHTIN, Mikhail. Os gêneros do discurso. In: BAKHTIN, Mikhail. Estética da criação verbal. São Paulo: Martins Fontes, 1992.p. 277-326.

BETTI, Mauro. Educação física como prática científica e prática pedagógica: reflexões à luz da filosofia da ciência. Revista Brasileira de Educação Física e Esporte, v. 19, n.3, p. 183-197, jul./set. 2005.

BRASIL, Ministério da Educação. Base Nacional Comum Curricular. Brasília: MEC/CONSED, 2015. Disponível em: <http://basenacionalcomum.mec.gov.br/\#/site/inicio>. Acesso em: $15 \mathrm{dez}$. 2016.

BRASIL, Ministério da Educação. Resolução n-2/2012. Diretrizes Curriculares Nacionais do Ensino Médio, 2012. Disponível em: <http://pactoensinomedio.mec.gov.br/images/pdf/resolucao ceb_002_30012012.pdf>. Acesso em: 15 dez. 2016.

BRASIL. Ministério da Educação. Parecer CNE/CEB № 15/98: Diretrizes Curriculares Nacionais Para o Ensino Médio. Brasília. 1998. Disponível em: <http://portal.mec.gov.br/cne/arquivos/pdf/ PCB15 1998.pdf >. Acesso em: 15 dez. 2016.

BRASIL. Ministério da Educação. Secretaria de Educação Básica. Parâmetros Curriculares Nacionais para o Ensino Médio: Parte II - Linguagens, Códigos e suas Tecnologias. Brasília, 2000.

BRASIL. Senado Federal. Lei de Diretrizes e Bases da Educação Nacional, no 9.394/1996. Brasília: Senado Federal, 1996. Disponível em: <https://www2.senado.leg.br/bdsf/bitstream/handle/ id/70320/65.pdf>. Acesso em: 15 dez. 2016.

DENTZ, Volmir von; LAMAR, Adolfo Ramos. Giros epistemológicos na filosofia e a virada linguística na filosofia da educação. In: SEMINÁRIO DE PESQUISA EM EDUCAÇÃO DA REGIÃO SUL, 7., 2008, Itajaí. Anais ... Itajaí: UNIVALI, 2008. p. 1-17.

FOUCAULT, Michel. A ordem do discurso. São Paulo: Loyola, 2008.

FOUCAULT, Michel. Microfísica do poder. Rio de Janeiro: Graal, 1988.

HOUAISS, Antônio. Minidicionário Houaiss de língua portuguesa, 4. ed. Rio de Janeiro: Objetiva, 2010.

LAZZAROTTI FILHO, Ari et al. O termo práticas corporais na literatura científica brasileira e sua repercussão no campo da Educação Física. Movimento, v. 16, n. 1, p. 11-29, jan./mar. 2010. 
RIO GRANDE DO SUL. Secretaria de Educação. Proposta pedagógica para o Ensino Médio

Politécnico e Educação Profissional Integrada ao Ensino Médio - 2011-2014. Porto Alegre:

SEDUC, 2011.

RIO GRANDE DO SUL. Secretaria de Educação. Referencial Curricular do Rio Grande do Sul: Lições do Rio Grande. Porto Alegre, SEDUC, 2009.

SAUSSURE, Ferdinand. Curso de linguística geral. São Paulo: Cultrix, 2006.

SILVA, Tomaz Tadeu. "Adeus às Metanarrativas Educacionais". In: SILVA, Tomaz Tadeu (Org.). O sujeito da educação: estudos foucaultianos. Petrópolis: Vozes, 1994. p. 247-258.

SILVA, Tomaz Tadeu. Documentos de identidade: uma introdução às teorias do currículo. Belo Horizonte: Autêntica, 2011.

VARELA, Júlio. O estatuto do saber pedagógico. In: SILVA, Tomaz Tadeu. 0 sujeito da educação: estudos foucaultianos. Petrópolis, RJ: Vozes, 1994. p. 87-96.

VEIGA NETO, Alfredo; LOPES, Maura Corcini. Identidade, cultura e semelhanças de família: as contribuições da virada linguística. In: BIZARRO, R.(Org.). Eu e o outro: Estudos Multidisciplinares sobre Identidade(s), Diversidade(s) e Práticas Interculturais. Porto: Areal, 2007. p. 19-35.

VEIGA-NETO, Alfredo. Foucault e a educação. Belo Horizonte: Autêntica, 2007. 
